\title{
Assembly line for the production of light gauge steel frame modular housing
}

\section{Linha de montagem para a produção de habitações em light steel frame}

\author{
André Luiz Vivan ${ }^{1}$ (1) José Carlos Paliari² \\ ${ }^{1}$ Universidade Federal de Itajubá - UNIFEI, Instituto de Recursos Naturais, Engenharia Civil, Itajubá, MG, Brasil. \\ E-mail: andreluizvivan@gmail.com \\ ${ }^{2}$ Universidade Federal de São Carlos - UFSCar, Departamento de Engenharia Civil, São Carlos, SP, Brasil. E-mail: \\ jpaliari@ufscar.br
}

How to cite: Vivan, A. L., \& Paliari, J. C. (2021). Assembly line for the production of light gauge steel frame modular housing. Gestão \& Produção, 28(2), e5213. https://doi.org/10.1590/1806-9649-

2020v28e5213

\begin{abstract}
For manufactured homes, the Light Gauge Steel Frame system does not have an indepth study on the relationship of its assembly techniques and the behavior of the production system based on assembly lines. Thus, this article presents the development of a flow shop production system using assembly lines for the production of Light Gauge Steel Frame modular houses. The main result was that the system was able to deliver a house in a little more than eight working hours, using four-hour cycles. For this, the article made use of experimental research procedure with the use of computational simulation. The abstracted model of the designed system was simulated, and its behavior analyzed concerning the hypothesis of improvement proposed in four different scenarios. The results can be considered relevant because it fills gaps in the body of knowledge in question with the use of the Light Gauge Steel Frame as a technology for the production of manufactured houses from assembly lines, also providing parameters of performance and design for the implementation of the proposed solution in the real estate market.
\end{abstract}

Keywords: Modular construction; Assembly line; Light gauge steel frame; Simulation; Performance evaluation.

Resumo: Para casas manufaturadas, o sistema Light Steel Frame não possui um estudo aprofundado sobre a relação de suas técnicas de montagem e o comportamento do sistema de produção baseado em linhas de montagem. Assim, este artigo apresenta o desenvolvimento de um sistema de produção flow shop, utilizando linhas de montagem para a produção de casas modulares em Light Steel Frame. O principal resultado do artigo mostra que o sistema proposto conseguiu entregar uma casa em pouco mais de oito horas de trabalho, usando ciclos de quatro horas. Para tanto, utilizou-se procedimento de pesquisa experimental com o uso de simulação computacional. O modelo computacional abstraído do sistema projetado foi simulado e seu comportamento analisado quanto às hipóteses de melhoria propostas em quatro cenários diferentes. Os resultados podem ser considerados relevantes porque preenchem lacunas no corpo do conhecimento em questão, a partir do uso do Light Steel Frame como uma tecnologia para a produção de casas fabricadas a partir de linhas de montagem, fornecendo também parâmetros de desempenho e projeto para a implementação da solução proposta no mercado imobiliário.

Palavras-chave: Construção modular; Linha de montagem; Light steel frame; Simulação computacional; Avaliação de desempenho.

Received Nov. 27, 2018 - Accepted June 28, 2019

Financial support:The authors gratefully acknowledge the Brazilian research funding agencies CNPq and FINEP for their financial support, and the PPGECiv/UFSCar for its practical support of this work. 


\section{Introduction}

The construction industry pursues alternatives to the new challenges of the market, since traditional practices are becoming increasingly inadequate in view of the continuous growth of the projects' complexity and also the need for speedy delivery (Koskela, 2000, 2011; Koskela \& Vrijhoef, 2001; Bertelsen et al., 2008). In this sense, changes in the technical production bases are fundamental in the construction industry. The use of flow shop production systems is appropriate for this context in which the assembly line is one of the techniques that best define the flow shop systems. Thus, the adoption of lines in the construction industry means that the houses, as final products, would be produced in a factory. In operational terms, the industrialized housing production process consists of several activities in an assembly line which should be well planned to ensure a solid construction (Mehrotra et al., 2003).

The question here is how to structure a flow shop system aiming the production of houses? What is involved and what interactions exist between the system elements? These questions need to be answered since the planning and operation of a plant must present a good balance between certain parameters such as the minimization of the throughput time and inventory, and the maximization of capacity utilization for better profitability (Müller et al., 2017).

Some studies were published considering the use of assembly lines for housing production, as: Hammad et al. (2004, 2008), Senghore et al. (2004), Mehrotra et al. (2005), Jeong et al. (2011), Arturo Garza-Reyes et al. (2012), Banerjee et al. (2006). In general, these articles deal with the design and use of assembly lines in the production of housing units, yet, none of them proposes or makes reference to the need for management of the assembly line when considering the optimization of its resources with intralogistics issues. In this sense, it is necessary to study the cause-and-effect relationship between the variables of processes and objectives regarding the system optimization as a whole, aiming at the best efficiency to be implemented. Furthermore, these publications do not suggest the use of Light Gauge Steel Frame (LGSF) as building technology, being the Wood Frame the technology associated.

In this way, the justification of the use of the LGSF is based on its industrialization characteristics inherent to its processes and sub-processes, regarding the characteristics of work on an assembly line. In addition, the LGSF, like any metallic structure, has another attribute represented by the dimensional accuracy, originated by the characteristics of the steel and by the manufacturing processes of the components. This accuracy may be more difficult to obtain with other materials commonly used in manufactured homes, such as wood for the Wood Frame system.

Therefore, this paper proposes the development of a flow shop production system using manual assembly lines as the production technique for LGSF housing units. Moreover, some hypotheses for optimization of different improvement goals associated with different simulation scenarios are presented. It is necessary to emphasize that, in this article, the analysis of the proposed system will be restricted to the aspects that refer to transportation velocities, production rates, productive times and idle times and efficiency of the layouts. No issues will be analyzed regarding the storage and supply of parts and components to the system.

In addition, the analysis of the proposed production system were developed based on the computational simulation of discrete events, as a scientific method of experimentation, in which the researchers developed a model to observe the operations of a system as a whole, conducting "What if" experiments for different scenarios (Long \& Zhang, 2014). In this way, the main model was elaborated that 
represented the attributes of the proposal and incorporated the variables used for the analysis that, in turn, were done with different scenarios, based on different hypotheses. Further details are described in the methodology.

Finally, it is necessary to show the reason for the development of this article and the reason for the presented analysis. The main justification for this study is the need to modernize construction processes in search of new constructive technologies as well as new methods of execution that break with traditional practices. Although the assembly line is a classic production technique, it is poorly understood and used in construction. In fact, it is a technique that allows the delivery of large volumes of production, an attribute that becomes important for construction, when we analyze the situation of countries with high rates of housing deficit. This is especially important in countries such as Brazil, where handicraft techniques still predominate in the construction industry with low volumes of housing production. This fact represents a broad field for the development of researches and real estate market, considering that the country has a housing deficit of more than 5 million of dwellings, a number that is incompatible with handicraft techniques of construction and represents a significant potential for the real estate market.

\section{Research gap and objectives}

Thus, according to what has been described previously, three main gaps could be identified: a) Considering assembly lines as a productive system of housing units, there is no mention of it is dedicated to products in LGSF; b) When it comes to system optimization, the publications do not explore the relationships and impacts between line attributes, processes, variables, and optimization goals in the system as a whole; c) In the selected publications, the results of the optimizations developed are based on the characteristics of existing plants, so that the results and analysis are linked to the context of these factories.

Thus, considering the selected publications, it can be noted that the research gap can be explained under two aspects: the technology and the linked technique of production, since it was not identified the use of LGSF as technology and the assembly line as a technique of production associated. Linked to these two aspects, the research gap is complemented by the need for understanding of the variables involved in production optimization processes. Thus, three research questions can be identified: 1) What is the layout of the production system that enables the development of the production activities in assembly lines for the production of housing units in LGSF? 2) What are the cause and effect relationships between the variables and attributes of the production system as a whole? 3) What scenario allows the best relationship among the variables from the intended optimization objectives?

Based on the research questions, this article has two main objectives: a) to develop the design of a production system based on an assembly line that includes the production of housing units in LGSF; B) optimize the designed system through the study of the relations between variables and attributes of the production system.

\section{Methodology}

The structure of the research consists, first, by the definition of an architectural housing unit in LGSF with the identification of key elements that define the house 
systems. This characterization is important because it delineates the assembly methods and constraints. The next step was to define the production system with its elements, constraints and processing times assignment. With this, the construction of the computational model was started, in which it was tried to replicate as accurately as possible the designed system. With the model defined and validated, the next step of the methodology was its computational simulation, which involved the optimization with the use of different scenarios.

It should be noted that ProModel ${ }^{\circledR}$ software was chosen as a tool in this article because it was indicated by specialists in computational simulation in construction sector. The software was acquired by the laboratory where the authors developed the present research as part of the tools that were used in a national research network that had the objective to propose and to develop solutions for the improvement of the productivity and of the conditions of work in the building sites. In addition, ProModel $\mathbb{R}$ is ideal for discrete event simulations, such as the models used in this article, as well as performing statistical analysis and calculations, and optimizing systems regarding the relationship between variables and improvement goals. The following are presented, in more detail, the steps of the methodology.

\subsection{Light Gauge Steel Frame housing unit}

The LGSF can be designed to meet all functional requirements characteristic of residential buildings, being suitable for industrialized production, so it can be considered a natural part of an industrial building process (Veljkovic \& Johansson, 2006). Thus, a housing unit linking four modules of equal dimensions was designed according to the technical and technological restrictions of the LGSF system. Regarding the modules, each one has dimensions restricted by two main factors: road transport and sealing plates. So, for usual road transportation, one of the module dimensions is $2.60 \mathrm{~m}$ (width) across the external studs, therefore excluding the external sealing plates, finishings and eaves. The second dimension, less restricted, was established according to the width of the sealing plates (and their joints); it was thus decided to use three Oriented Strand Board (OSB) and their respective joints, resulting in $3.59 \mathrm{~m}$ length. The ground floor plan of the housing unit can be seen in Figure 1.

Each module has an independent structure, which ensures the support of its slab and coverage without the need for special or temporary structures, so that, once completed, they only need to be coupled to each other according to the layout of the architectural plan. Below there are some more specific attributes of the housing units and their elements. The designed unit consists of five rooms divided into four $9.42 \mathrm{~m}^{2}$ modules each, totaling $37.66 \mathrm{~m}^{2}$, including finishing. The ceilings of each module are $2.50 \mathrm{~m}$ high, also including the finishing on the floor and slab. The eaves of the house are $0.30 \mathrm{~m}$ wide and go forward on all sides of the building. The structure for the modules floor is composed of floor beams and rim joists at the edge of the element. All floors have four rim joists delimiting their area and serving as support for the floor beams towards the smaller gap. The floors of the four modules are soundproofed after assembling of the structure. The OSBs are fixed on both sides of the structure and isolation is set, so that the floor face, which will be in contact with the foundation, receives isolation through a water-resistant insulation.

All of the housing units walls are composed of the same kind of wall tracks and studs. The openings for windows are the same size in all the walls where they are needed so that the shapes forming the sills and headers are equal and can be used in 
any wall (the same applies to the door openings). Thus, any studs and/or tracks can be used on any wall, whether it is external or internal, as long as the worker knows what was designed. All the walls also receive thermal insulation installed between studs. On the structure and isolation set, on the inner side of the modules, the plasterboards are installed with joints properly treated after fixing. OSBs are installed on the outside of the modules and coated with water-resistant insulation after fixing.

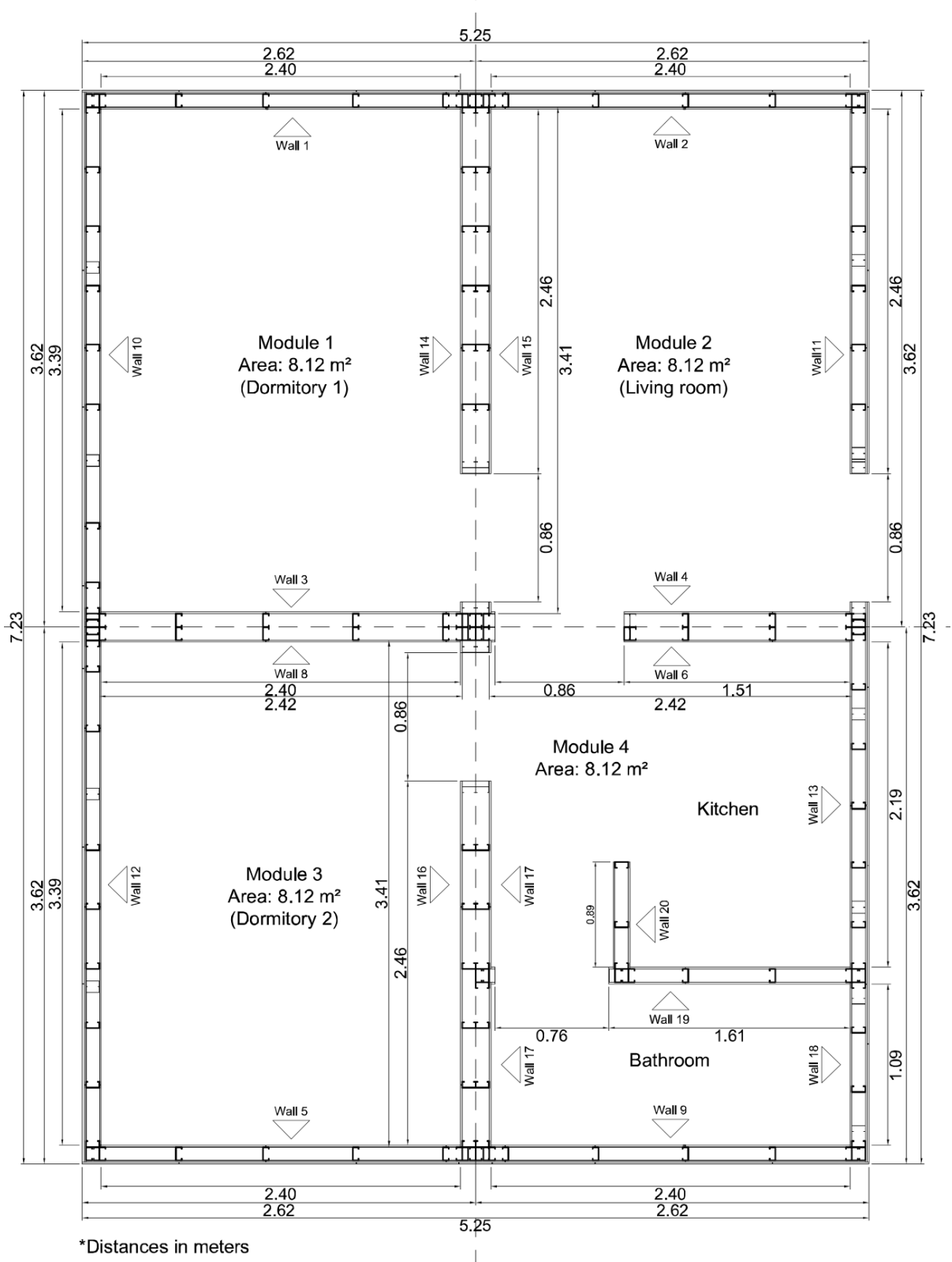

Figure 1. Plan of the housing unit composed of four modules.

The slab structure is similar to the floor's, being also composed of rim joists and beams. The beams follow the same modularization of the walls studs, on which they are positioned. The slabs also receive thermal insulation and are only coated on their 
underside with plasterboard plates that also receive joints treatment after fixing. The slabs also support the roof trusses, so that they are fixed on the upper tracks of the walls. The entire module roof is supported by trusses, which in turn are supported on the beams of the slabs. The OSBs, which will support the subsequent fixing of the shingle tiles, are fixed on the trusses. The fixing of the shingle is not made entirely in the production system, once the remaining parts covering the connecting joints between modules are properly fixed in the final installation.

The plumbing system is restricted to Module 4, where the bathroom and the kitchen of the unit are. The hydraulic network assembly and installation techniques follow traditional procedures. The water distribution system consists of three kits (assembled with Crosslinked Polyethylene (PEX) pipes) which are fixed in the corresponding studs for the connection of: bathroom sink faucet, shower, and kitchen faucet. The necessary links between these kits and the distribution network were also done with PEX pipes. Sanitation was designed considering the use of Polyvinyl Chloride (PVC) pipes preassembled, with fitting ends in the bathroom and kitchen. For the electrical installation, was used PVC conduit, passed through and fixed between studs and slab beams. As in the plumbing system, the electrical installation also follows the same traditional techniques. It has to be emphasized that the wiring of each module is on hold to be later connected to their correspondent circuit breakers.

For modules 1, 2 and 3 precut wallpaper was used as finishing for the walls, and wood veneer also previously cut was used on the floors. On Module 4, walls and floors were coated with vinyl as these are wet areas. Externally all modules are coated with vinyl siding set on water-resistant insulation. The doors and windows come in kits fixed with polyurethane foam in their corresponding openings. Finally, the fixation of baseboards, joint finishings and other finishing activities, are performed while the modules are still separated. The remaining outer and inner joints resulting from the coupling between modules are properly finished after the final installation.

\subsection{Production system design}

According to Rekiek \& Delchambre (2006), the design of an assembly line involves the integration of the products' design, processes and plant layout. The manufacture of an item on the assembly line is divided into a set of well-known tasks, where each workstation is assigned a subset of tasks named "station workload". Each task demands a certain operation time that should be determined by the technologies and resources used (Bautista \& Pereira, 2007).

Thereby, a manufactured house is produced in a factory controlled environment and, once complete, is transported to the final destination where it is installed and connected with the other facilities such as foundations and hydraulic systems (Mehrotra et al., 2005). The authors show that for the housing unit assembly, several workstations of different types that may be grouped in main lines, production cells or feeding lines are necessary. Additionally, the workstations must be suitable to hold the necessary tools and machines for the completion of the assigned activities. After conducting several case studies in various related industries, Hammad (2001) and Mehrotra et al. (2005) suggest a task division on the house's assembly to be used in assembly lines, regardless of the construction technology.

The task division suggested by the authors can be understood as a possible starting point for the design of new systems of house production. Thus, this division of tasks presented by Hammad (2001) and Mehrotra et al. (2005) was adopted as the starting 
point for the project development of this paper's resulting system. However, the information provided by the authors refer to the number of workstations and the activities assigned to each of them, lacking information on the dimensional attributes and workflow, which were defined below.

The design process of the production system demands the setting of its operational characteristics and dimensional attributes. This is especially important for those attributes that define the space between the workstations. Otherwise, the analysis would be too simplistic, not reflecting a real situation. Therefore, the distance between the workstations and the transportation flow between them were defined. It is important to emphasize that the solutions adopted are feasible and can be applied in a real situation.

The production system is composed of a main "U" shaped assembly line, besides three other feeding lines and production cells. The main line, called Alpha line, was designed in $U$ shape with a linear length of 385 meters, consisting of 15 workstations and two inspection points. This line receives LGSF elements from 3 feeding lines, Beta and Gamma lines with 22 meters and Delta line with 62 meters. The feeding lines are structured for three workstations each, except for the Delta line that has four workstations. The structure for receiving the assembly activities is called platform, which is transported along the lines by rails that follow the course of the lines. Finally, there are 10 production cells that process components for use in the feeding lines and in the main line. Table 1 shows the activities assigned to the main and the feeding lines and the allocation of tasks to the production cells.

Table 1. Workstations, production cells and assigned tasks.

\begin{tabular}{|c|c|}
\hline Workstation & Tasks description \\
\hline \multicolumn{2}{|c|}{ I - Alpha main line } \\
\hline Alpha 1 & $\begin{array}{l}\text { Alignment and platform preparation; Assembly of the floor structure and } \\
\text { bottom sealing }\end{array}$ \\
\hline Alpha 2 & Hydraulic kits installation \\
\hline Alpha 3 & Insulation and substratum boards placement \\
\hline Alpha 4 & Internal walls fixing \\
\hline Alpha 5 & External walls fixing \\
\hline Alpha 6 & Slab and roof fixing \\
\hline Inspection & LGSF structure inspection \\
\hline Alpha 7 & Electrical wiring, installation of switches and electric outlets \\
\hline Alpha 8 & Walls insulation placement, OSB and water-resistant insulation fixing \\
\hline Alpha 9 & Vinyl siding fixing \\
\hline Alpha 10 & $\begin{array}{l}\text { Fixing of OSB and PVC on the eaves and shingle tiles fixing; Fixing of } \\
\text { doors and windows }\end{array}$ \\
\hline Alpha 11 & Slab coating; Internal walls coating \\
\hline Alpha 12 & Slab coating; Internal walls coating \\
\hline Alpha 13 & Floor coatings \\
\hline Alpha 14 & Porcelain, metal accessories and shower fixing \\
\hline $\begin{array}{l}\text { Alpha } 15 \text { and } \\
\text { final inspection }\end{array}$ & Internal and external finishings; Final finishings inspection \\
\hline \multicolumn{2}{|c|}{ II - Beta, Gamma and Delta Feeding Lines } \\
\hline Beta 1 & Position tracks and studs; screw both sides \\
\hline Beta 2 & Pass conduits; insulation fixing; plasterboard fixing \\
\hline
\end{tabular}


Table 1. Continued...

\begin{tabular}{ll}
\hline Beta 3 & Treatment of joints between boards \\
\hline Gamma 1 & Position tracks and studs; screw both sides \\
\hline Gamma 2 & Pass conduits; insulation fixing; plasterboard fixing \\
\hline Gamma 3 & Treatment of joints between boards \\
\hline Delta 1 & Position beams and rim joists; screw both sides \\
\hline Delta 2 & Pass conduits; placement of insulation; plasterboard fixing \\
\hline Delta 3 & Treatment of joints between boards \\
\hline Delta 4 & Roof fixing \\
\hline III - Production Cells \\
\hline C-2 & Processing of the hydraulic tubes connection for sanitation: kits assembly; \\
\hline C-8 & $\begin{array}{l}\text { Processing of the insulating blankets, OSB cuts and cuts in the water- } \\
\text { resistant insulation; }\end{array}$ \\
\hline C-9 & Cuts and adjustments on vinyl sidings; \\
\hline C-10 & $\begin{array}{l}\text { PVC processing for the eaves lining and cuts for adequation of the shingle } \\
\text { tiles; }\end{array}$ \\
\hline C11 & Cuts in the slab coating; Wallpaper and vinyl cuts; \\
\hline C-13 & Laminated flooring and vinyl cuts; \\
\hline C-15 & Cuts and adjustments in joints finishing; \\
\hline C- $\beta 2$ & $\begin{array}{l}\text { Cuts and adjustments in the plasterboards plates, conduits, passage } \\
\text { boxes and hydraulic kits; }\end{array}$ \\
\hline C-ץ2 & $\begin{array}{l}\text { Cuts and adjustments in the plasterboards plates, conduits, passage } \\
\text { boxes and hydraulic kits; }\end{array}$ \\
\hline C- 54 & Assembly of trusses; fixation of OSB on the trusses. \\
\hline
\end{tabular}

For the Alpha line the "U" shape was chosen because, in this arrangement, the workers can be placed in the center of the layout, allowing monitoring and mutual assistance when necessary (Rekiek \& Delchambre, 2006). In this sense, as stated by Miltenburg (2001a), the central space of the line becomes an area of information exchange and mutual learning. Miltenburg (2001b) shows that in this format, the production flow and the movement of the operators may be assigned both clockwise and counterclockwise. For this configuration, the author recalls the fact that there is a constant stock of Work in Process (WIP) between workstations, which also allows the imbalance visualization.

It was also considered that all the workstations activities are done on the assembly platforms with dimensions that comprise the area occupied by a module of the housing unit, being at a height that allows the work of the workers. To do this, the platforms were configured with 4.40 meters wide by 5.20 meters long. The distance between workstations, considering the dimensions of the platforms, was 5.80 meters, enough to admit one platform that is waiting to enter on the next workstation.

Regarding the flow lines, it was suggested the adoption of a system called cart-ontrack, as it does not require high levels of automation and allows the workers to control the movement themselves. Tompkins \& White (1984) show that the mechanism of this system is based on a rotating tube, the rails and the platform. According to Aized (2010), the operation is relatively simple and can be described as follows: the platform is engaged on the rails and moved by the rotating tube; this tube is connected to a drive wheel which can be rotated at angles ranging from 0 to $45^{\circ}$; thus, different velocities can be obtained by varying the angle. Therefore Tompkins \& White (1984) show that the platforms can be controlled independently allowing the allocation of many platforms 
on the rails. This is possible as the platforms can stand still when the drive wheel is parallel to the rotating tube.

Along the lines, there are certain points where there it is necessary to change the direction of the platforms because of their return and the system layout. In this case, turning points, in which the rails are rotated in order to align them with the new route, were considered. This mechanism, known as round track, is structured on the rails of the assembly lines and allows the necessary direction changes when it is not possible or feasible to use mats. Figure 2 shows the layout of the proposed system, with flow orientation and other necessary considerations for the operation. This layout was used for the simulation of scenarios 1 and 2 .

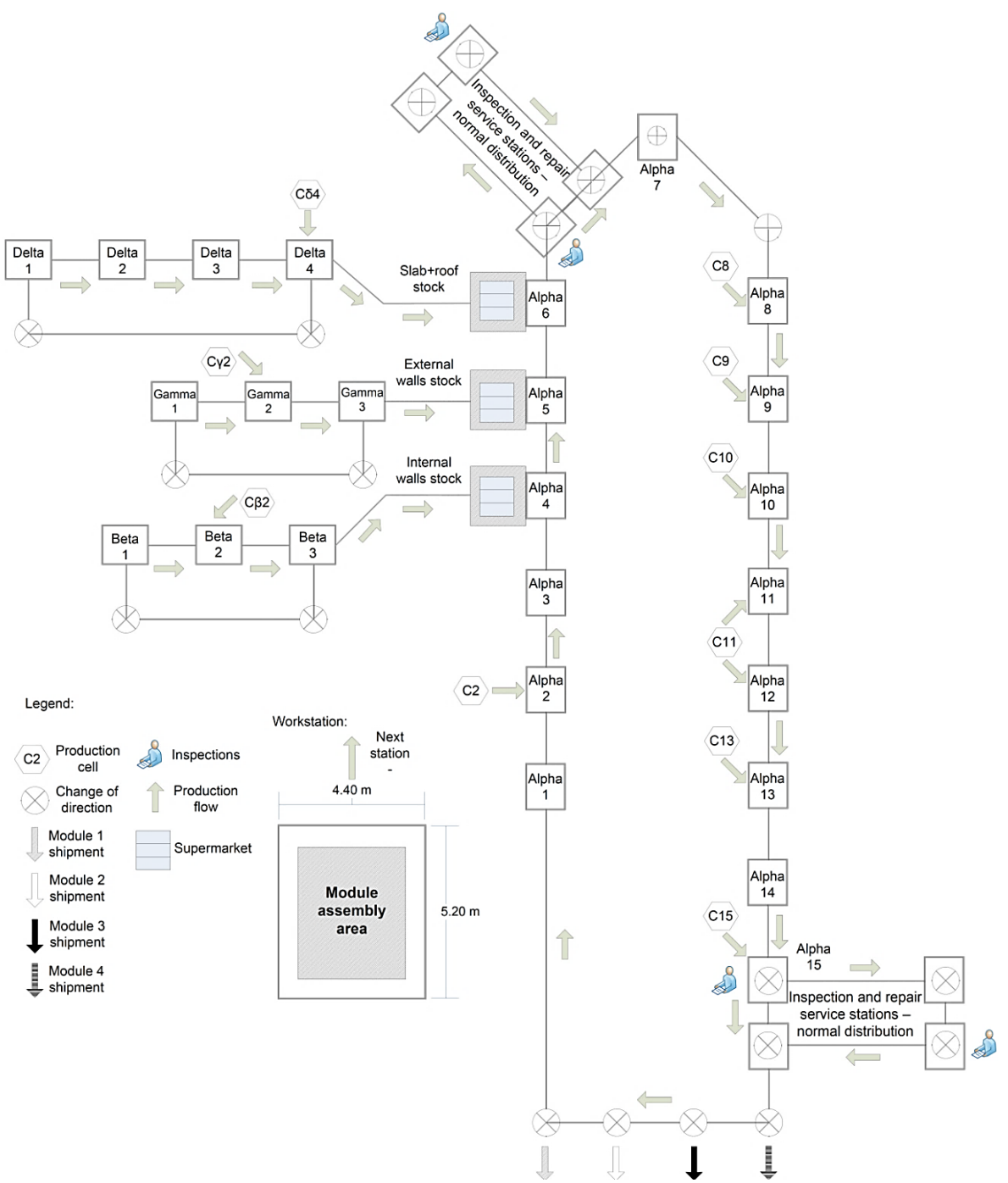

Figure 2. Layout of the production system used for the simulation of scenarios 1 and 2 .

\subsection{Processing times}

Each workstation performs activities for the processing of different elements and/or components. Therefore, the processing times of each workstation vary according to 
purpose, tools and/or machinery being used and the number of workers performing these activities. The times of each task were calculated based on construction productivity indexes for the LGSF system and also based on data collected in residential constructions using this building system. It should be noted that certain conditions have been pre-established for the calculation of the processing times, as follows: 1) All activities follow a sequence that is defined by the assembly design of each module element; 2) For each workstation the movements are performed by an assembler and an assistant; 3) Where there are large components or elements supermarkets, the assembler and the assistant will move to load and transport such components, influencing the final value of the processing time; 4) Where there are small components or elements supermarkets, only the assistant moves for loading and transporting, which does not impact the final value of the processing time; 5) All components in the supermarkets are arranged on the floor, obliging the workers to get down to load; 6) The screwing activities are all performed with electric screwdrivers.

Thus, for the main line, the processing times of the modules at each workstation are assigned in Table 2 as well as the allocated teams. For the feeding lines, the processing times of the elements can be seen in Table 3. There are two workers allocated for each of the stations of the feeding lines.

Table 2. Standard processing times on the main line and allocated teams.

\begin{tabular}{lccccc}
\hline Workstation & $\begin{array}{c}\text { Team } \\
\text { (workers) }\end{array}$ & $\begin{array}{c}\text { Module 1 } \\
\text { (minutes) }\end{array}$ & $\begin{array}{c}\text { Module 2 } \\
\text { (minutes) }\end{array}$ & $\begin{array}{c}\text { Module 3 } \\
\text { (minutes) }\end{array}$ & $\begin{array}{c}\text { Module 4 } \\
\text { (minutes) }\end{array}$ \\
\hline Alpha 1 & 2 & 33.00 & 33.00 & 33.00 & 33.00 \\
\hline Alpha 2 & 2 & 0.00 & 0.00 & 0.00 & 22.00 \\
\hline Alpha 3 & 2 & 26.00 & 26.00 & 26.00 & 26.00 \\
\hline Alpha 4 & 2 & 7.00 & 7.00 & 7.00 & 12.00 \\
\hline Alpha 5 & 2 & 7.00 & 7.00 & 7.00 & 7.50 \\
\hline Alpha 6 & 2 & 12.00 & 12.00 & 12.00 & 12.00 \\
\hline Inspection & 1 & 5.00 & 5.00 & 5.00 & 5.00 \\
\hline Alpha 7 & 2 & 18.50 & 18.50 & 18.50 & 25.00 \\
\hline Alpha 8 & 4 & 21.50 & 21.50 & 21.50 & 21.50 \\
\hline Alpha 9 & 4 & 31.50 & 31.50 & 31.50 & 31.50 \\
\hline Alpha 10 & 4 & 30.40 & 30.40 & 30.40 & 30.40 \\
\hline Alpha 11 & 6 & 20.65 & 20.65 & 20.65 & 24.25 \\
\hline Alpha 12 & 6 & 20.65 & 20.65 & 20.65 & 24.25 \\
\hline Alpha 13 & 2 & 35.00 & 35.00 & 35.00 & 35.00 \\
\hline Alpha 14 & 2 & 0.00 & 0.00 & 0.00 & 30.00 \\
\hline Alpha 15 +Final & 5 & 35.00 & 35.0 & 35.0 & 40.00 \\
\hline inspection & & & & &
\end{tabular}

Table 3. Standard processing times in the feeding lines.

\begin{tabular}{lllll}
\hline \multicolumn{1}{c}{ Element } & \multicolumn{3}{c}{ Workstations and associated time (minutes) } \\
\hline Internal wall 3 & $\beta 1(3.20)$ & $\beta 2(12.90)$ & $\beta 3(12.90)$ & - \\
\hline Internal wall 14 & $\beta 1(7.40)$ & $\beta 2(15.30)$ & $\beta 3(15.30)$ & - \\
\hline External wall 1 & $\gamma 1(4.60)$ & $\gamma 2(12.90)$ & $\gamma 3(12.90)$ & - \\
\hline External wall 10 & $\gamma 1(7.80)$ & $\gamma 2(15.30)$ & $\gamma 3(15.30)$ & - \\
\hline Slab and roof 1 & $\delta 1(12.40)$ & $\delta 2(17.00)$ & $\delta 3(17.00)$ & $\delta 4(24.80)$ \\
\hline
\end{tabular}


Table 3. Continued..

\begin{tabular}{lcccc}
\hline \multicolumn{1}{c}{ Element } & \multicolumn{3}{c}{ Workstations and associated time (minutes) } \\
\hline Internal wall 4 & $\beta 1(5.70)$ & $\beta 2(12.90)$ & $\beta 3(12.90)$ & - \\
\hline Internal wall 15 & $\beta 1(8.20)$ & $\beta 2(15.30)$ & $\beta 3(15.30)$ & - \\
\hline External wall 2 & $\gamma$ 1 (4.60) & $\gamma 2(12.90)$ & $\gamma 3(12.90)$ & - \\
\hline External wall 11 & $\gamma$ 1 (9.00) & $\gamma 2(15.30)$ & $\gamma 3(15.30)$ & - \\
\hline Slab and roof 2 & $\delta 1(12.40)$ & $\delta 2(17.00)$ & $\delta 3(17.00)$ & $\delta 4(24.80)$ \\
\hline Internal wall 8 & $\beta 1(3.20)$ & $\beta 2(12.90)$ & $\beta 3(12.90)$ & - \\
\hline Internal wall 16 & $\beta 1(7.40)$ & $\beta 2(15.30)$ & $\beta 3(15.30)$ & - \\
\hline External wall 5 & $\gamma 1(4.60)$ & $\gamma 2(12.90)$ & $\gamma 3(12.90)$ & - \\
\hline External wall 12 & $\gamma 1(7.80)$ & $\gamma 2(15.30)$ & $\gamma 3(15.30)$ & - \\
\hline Slab and roof 3 & $\delta 1(12.40)$ & $\delta 2(17.00)$ & $\delta 3(17.00)$ & $\delta 4(24.80)$ \\
\hline Internal wall 6 & $\beta 1(5.70)$ & $\beta 2(12.90)$ & $\beta 3(12.90)$ & - \\
\hline Internal wall 17 & $\beta 1(7.40)$ & $\beta 2(15.30)$ & $\beta 3(15.30)$ & - \\
\hline Internal wall 19 & $\beta 1(5.70)$ & $\beta 2(12.90)$ & $\beta 3(12.90)$ & - \\
\hline External wall 9 & $\gamma 1(4.60)$ & $\gamma 2(12.90)$ & $\gamma 3(12.90)$ & - \\
\hline External wall 13 & $\gamma 1(6.10)$ & $\gamma 2(10.40)$ & $\gamma 3(10.40)$ & - \\
\hline External wall 18 & $\gamma 1(2.70)$ & $\gamma 2(4.55)$ & $\gamma 3(4.55)$ & - \\
\hline External wall 20 & $\gamma 1(1.50)$ & $\gamma 2(4.15)$ & $\gamma 3(4.15)$ & - \\
\hline Slab and roof 4 & $\delta 1(12.40)$ & $\delta 2(17.00)$ & $\delta 3(17.00)$ & $\delta 4(24.80)$ \\
\hline
\end{tabular}

\subsection{Simulation model}

Simulation is an essential tool on the proposition for a solution of several problems that happen in real life (Banks, 1999). The author shows that simulation is used to describe and analyze the behavior of a process through questions such as "What if?" aiding the design of real processes. Most of the prediction simulation models are used in the processes and operations management as, for example, inventory control, quality control, productivity and production flow (Dooley, 2002). A computational model can be interpreted as a tool used to represent some systems for a defined purpose being, generally, simplified abstractions that include only the scope of action and certain levels of detail, necessary to meet the research objectives (White \& Ingalls, 2009). Thus, the simulation involves the creation of a model that mimics the behavior or situation being studied, enabling the observation and understanding of the results (White \& Ingalls, 2009).

For the modeling of the proposed system, the following assumptions were assumed: the model will not contemplate questions related to the supply of parts and components and their storage; the transportation velocity of the platforms between the workstations is constant, but it assumes an ideal value based on the optimization between the demand and the variables of each scenario; the productivity of workers at each workstation is variable; demand is fixed; the line is mixed (four different modules); the assembly order coordination system of the modules is based on the use of Kanban; internal, external and roofing panels are provided by feeder lines for the main line; modules that require repairs after inspections are moved from the main line and then returned; the main line assumes the format " $U$ "; between the workstations there is space for the storage of platforms with unfinished modules.

Considering the development of the simulation in ProModel $囚$ software, each of the workstations of the main line and of the feeder lines was defined as a location that, in 
this case, was responsible for the performance of the assembly activities of the modules and their elements. It should be noted that each workstation was configured with FIFO (First In First Out) rule, as a condition for receiving and releasing entities to be processed or already processed. Between workstations and between the feeder lines and the main line, networks of paths have been defined in which the software understands as the route that must be obeyed for the transportation of the elements and modules with the platforms. For each path network, nodes have been defined which, in turn, are located in the center of each location (workstation). Therefore, in the model, four path networks associated with the four lines were defined: alpha network, beta network, gamma network and delta network.

With respect to resources, in ProModel ${ }^{\circledR}$, they are responsible for the actions during the simulation. Thus, in the case of transportation activities, the resources were defined: by the platforms allocated to specific nodes of the path networks; by the forklift responsible for the transportation of the panels and slabs of the feeder lines to the main line; and the crane responsible for the transportation of the panels and slabs for use on the main line. Additionally, each of these transport features has attributes such as velocity, starting point, acceleration among others that have been informed to the software and have changed or not, depending on the scenario.

Regard the allocation of workers in each workstation, whose teams are defined in the results and discussions section, is also included in the construction of the model. In addition to the allocation of workers, the software also allows to configure the performance of each one through some specifications such as the typical actions of assembly tasks, e.g. "pick up" and "deposit", which are associated with the activities assigned to workstations. These two attributes are set in terms of time consumption in the order of seconds defined according to the need of each simulation scenario.

With these definitions, it was possible to construct the model logic. Thus, with respect to the sequence of the activities of the lines, the programming logic is defined by: declaration of the element to be processed, declaration of the location where this activity will occur, declaration of operations, declaration of the outputs, declaration of the destination of these outputs (next station or other location), declaration of the routing rule and transportation declaration. In the sequence were declared the arrivals that, for ProModel $\AA$, mean information about the quantities to be produced for each element or module, the frequency of arrival and the location where these products arrive for the first time among other commands. In the case of this article, the demand was defined as being 500 housing units and, therefore, the occurrences of each of the created elements (walls, slabs, floors and roofs) correspond to this value.

\subsection{Model operation logic}

The variables should be specified in order to make clear which results are being measured. Thus, Creswell (2010) shows that it should be clear in the models what the independent variables are (those which influence the results) and what the dependent variables are (those which represent the results of the independent variables influence). As explained, all the modules transportation along the lines is done through the platforms. Therefore, it was necessary to not only declare and assign platforms as transport, but also determine the best number of this resource in the lines and their respective speed, regarding the optimization objectives of each scenario. Such platform attributes are classified as independent variables of the model. The dependent 
variables are: Cycle time (C); Lead time; Work in Process (WIP); Waiting and blocked times, and System efficiency $(E)$, which are contextualized in the simulated scenarios.

Within the context of the operating logic of the model, it should be emphasized that it was programmed based on the assumptions of Just-in-Time (JIT) in association with Kanban in programming the production orders. Thus, some of the variables listed above were also used for programming the JIT system in the models. Associated with such variables, attributes, which are specific to the programming, which admits absolute values for each scenario, and are necessary for the calculation of dependent variables were also created. The calculation of the cycle times, production times, WIP, etc., was done from the insertion of these variables in certain command lines of the models, in association with some commands reserved to ProModel $\circledast$. For example, for programming the JIT the following code was used (example for module 1):

Order_Module_1// (entity representing the kanban card)

SEND 1 Module_1 TO Station_Alpha_1 JOIN 1 Module_1// (Process)

For the cycle times, the following code was used (example for module 1):

1 Cycle_Time_Mod_1=Clock()-Start_Mod_1

2 INC Mod_1_Complete

3 INC Mod_1_Total_Time, Cycle_Time_Mod_1

4 Average_Cycle_Time_Mod_1=Mod_1_Total_Time/Mod_1_Complete

The results of such parameters were also used to calculate other values that also served as the basis for the performance comparison among different scenarios, such as the efficiency of the lines, the system cycle time, among others.

\subsection{Model stochastic attributes}

According to Schmitz et al. (2002), variability issues can be divided into process and flow variability. For Hopp \& Spearman (2008) a high variability involves long cycle times, high levels of WIP, production capacity wastage and loss of revenue. In fact, the effects of variability are easily observed in many traditional construction sites, considering their working conditions. However, in a factory environment, variability tends to be reduced due to the higher levels of control processes.

Process variabilities were considered in the model of this article. Therefore, the variation percentages were obtained given that, according to Lane (2007), in lowvolume production systems, it is usual that the times vary within a plus or minus $15 \%$ interval. The author considers this variation acceptable and that the system usually equalizes it along the workstations. In addition, no data was found regarding the variation of time in a case similar to the model of this article, so that the information available stipulate variations observed in machines and workers in environments and contexts that differ, depending on the publication of the study, with no consensus.

With this variation, the times of the workstations described in the results section should be understood as the activities standard processing times, having upper and lower limits set by the variation described $(+15 \%$ and $-15 \%)$. Thus, the lead time associated to each worker's task in the workstations (Table 3) varied within these limits. Consequently, with the maximum and minimum ranges of each workstation, it became necessary to assign the best statistical curve for this variation modeling. For this, the StatFit $\AA$, another software that works in conjunction with ProModel $\circledR$ was used. StatFit ${ }^{\circledR}$ is a statistics software that helps, among other utilities, the user on the choice of the statistical curve that fits in the reported data. 
The results obtained from StatFit $@$ report several parameters of the descriptive statistics. In addition, the best statistical curve that describes the variation of data in each job is shown. So, time variations were inserted for all the workstations. Once the descriptions of the data and the suggested curves are analyzed, it is necessary that the selected statistics curve be exported to the simulation model programming. Analyzing the StatFit $₫$ results, it was concluded that the Beta distribution was the best curve for the variation. The programming of the processing times according to the selected curve happens automatically in ProModel ${ }^{\circ}$ and, in the case of the Beta distribution, the processing time of a specific activity is exported to the standardized format, $B(\alpha, \beta, C, D)$, where: $\alpha=$ order coefficient that should be greater than zero; $\beta$ = shape coefficient that must be greater than zero; $C=$ lower limit of the curve; $D=$ upper limit of the curve.

The variability of processes assigned to the model sets the stochastic character of its computational simulations. Also, being a stochastic model means that their behavior is something closer to what would be observed in a real production system, since, as it is composed of manual lines, the process variability is more recurrent, although it may be better controlled for being a factory environment.

\subsection{Model validation and replications}

The computational model and its optimizations were simulated and validated in view of some parameters observed and measured along the simulations. In general, for the conduct of the simulations were obeyed the steps for simulations conduct and validation proposed by Law \& Kelton (2000). The main indicators used for the validations involved a comparison between the quantity delivered of modules in the main line and the number of production orders released. In addition, ProModel ${ }^{\circ}$ enables the monitoring of the simulation through the animation of the layout versus the programming provided, which facilitated the observation of the behavior of resources and entities along the workstations.

It is noteworthy that the simulated models have been passed through an extensive period of development and refinement. During the tests of the first versions, several irregularities were identified. In this context, it can be emphasized the problems found in the programming and logic of the paths that should be covered by the platforms, and the need to join the elements produced in the feeder lines with the modules being processed in the main line. In addition, other irregularities were found during the tests, so that all were corrected. Corrections were considered effective for two reasons: 1 ) the models behaved as expected in a real case, except for the simplifications of the model; 2) the final results were as expected, being consistent with all values and logics attributed to programming.

With the validated models, it was also necessary to determine the number of replications required for the simulation. The replications aim to give a greater accuracy of the results from the repetition of the simulation, ensuring that they are within a desired confidence interval. For this, the StatFit $₫$ was used again, for which the following parameters were supplied:

- Confidence level - 95\%

- Parameter variation - minimum of 34 and maximum of 46 for a processing time of 40 minutes;

- Range for estimate $-3,589$. 
The adopted confidence level of 95\% represents the estimated interval where the means of the chosen parameters are likely to occur. The parameter variations adopted come from the minimum and maximum times of the workstation Alpha 15 (to be demonstrated). This station was chosen because it had the longest processing time and, consequently, the largest variation among all the others. The range for estimate was provided based on the standard deviation of the time series adopted, consisting of 500 stipulated variations for the processing time of the Alpha 15, always respecting the range of $+15 \%$ and $-15 \%$. With these parameters, StatFit $₫$ indicated the need to perform at least 7 replications for each scenario.

It is also necessary to point out that such validation refers to the cases structured and analyzed in each of the scenarios described in this article. In this sense, the inclusion or exclusion of other variables (dependent or independent), necessarily, must generate new models that, in turn, must be validated.

\section{Results}

Altogether, four scenarios were simulated that incorporated modifications to reduce unproductive times and cycle times. Scenario 1 was simulated with the model in its initial state, as shown in Figure 2. Scenario 2 is represented by the optimization of scenario 1. Such optimization took into account the need to reduce the cycle time of the modules and minimize the idle time of the workstations. Scenario 3 contemplated physical changes in the layout to evaluate the behavior of the system and, for this scenario, feeder lines were eliminated for a possible reduction of cycle time and unproductive times. Finally, for scenario 4 , new physical changes were made by reducing the number of workstations. In this case, stations 5 and 6 were eliminated and their respective tasks were grouped in station 4 .

In order to summarize what was done in each scenario, Table 4 presents the objectives that stimulated the optimizations of scenarios 2, 3 and 4 (scenario 1 represents the results of the initial state of the productive system and, therefore, does not present any optimization), as well as how these objectives were achieved.

Table 4. Summary of objectives and tactics for scenario optimization.

\begin{tabular}{cll}
\hline Scenario & \multicolumn{1}{c}{ Objective } & \multicolumn{1}{c}{ How } \\
\hline Scenario 2 & $\begin{array}{l}\text { Reduce the delivery cycle time and } \\
\text { minimize the waiting and idle times } \\
\text { in the stations, it is necessary }\end{array}$ & $\begin{array}{l}\text { Increasing the supply of assembly } \\
\text { platforms on the main line and on the } \\
\text { feeding lines, adjusting the transport } \\
\text { velocity }\end{array}$ \\
\hline Scenario 3 & $\begin{array}{l}\text { Reduce cycle time and } \\
\text { unproductive times }\end{array}$ & $\begin{array}{l}\text { Changing the system layout - } \\
\text { eliminating the feeding lines }\end{array}$ \\
\hline Scenario 4 & $\begin{array}{l}\text { Reduce cycle time and increase } \\
\text { system efficiency }\end{array}$ & $\begin{array}{l}\text { Changing the system layout - } \\
\text { supression of stations 5 and 6 and } \\
\text { group their tasks in station 4 }\end{array}$ \\
\hline
\end{tabular}

The details and results of each scenario are presented below.

\subsection{Scenario 1 simulation}

Before the simulation of the model, it is important to check the distribution of the workload between the stations. Work distribution directly affects system performance. Very uneven distributions can cause high rates of station blocking, 
generating delays in the system. The main parameter for this verification is the Smoothness Index (SI). According to Scholl (1999), the SI (dimensionless parameter) calculation takes into account the cycle time of the slowest station and the processing times of the other stations (standard times), obeying Equation 1, where $\mathrm{C}$ is the cycle time determined by the slowest workstation processing time and $t(\mathrm{Sk})$ is the processing time relative to each station $k$ (in Table 2). Thus, the slowest station corresponds to Alpha 15. Considering that Module 4 is the product that overloads the line, the processing time of station Alpha 15 (40 minutes) of this module was adopted for the SI calculation, resulting in $\mathrm{SI}=67.42$. According to Scholl (1999), the closer to zero is the value of $\mathrm{SI}$, better distributed is the workload between the stations. Thus, it is noted that this first value (67.42) is relatively high, due to the differences in processing times between the most charged workstations and between the fastest workstations.

$\mathrm{SI}=\sqrt{\sum_{\mathrm{k}=1}^{\mathrm{M}}(\mathrm{C}-\mathrm{t}(\mathrm{Sk}))^{2}}$

his first simulation aims to demonstrate the performance of the designed production system in its original state (as shown in Figure 2). This performance was measured through the results provided by ProModel $\AA$, being used as a benchmark for the performance analysis of the other scenarios. A fictitious demand of 500 housing units was adopted in all the scenarios; in other words, the production system must deliver 500 units of each module for such demand. The independent variables involved in this scenario are those related to the main line and to the feeder lines platforms. These variables assumed initial values of quantity and velocity, being 4 platforms for the Alpha line and 1 platform for each feeder line. The initial velocity assigned was $1.11 \mathrm{~m} / \mathrm{s}$ for all platforms. With the model variables properly configured, the simulation started. The results of this first scenario are in Table 5.

In Table 5 it is noted that the values of cycle times are very close, partly due to the similarity of processing times at the stations. In spite of the cycle time being relatively low by the standards of the construction industry, it is necessary to analyze the behavior of the workstations taking into consideration the activities that add and do not add value, as these activities directly influence the composition of the lead time and its magnitude. Considering the behavior of the workstations, the percentages related to the behavior of the main line and feeding lines stations are in Table 6.

Table 5. Modules and housing unit cycle times for scenario 1.

\begin{tabular}{cccc}
\hline Product & $\begin{array}{c}\text { Average cycle time } \\
\text { (minutes) }\end{array}$ & $\begin{array}{c}\text { Average lead time } \\
\text { (minutes) }\end{array}$ & WIP max \\
\hline Module 1 & 521.66 & 261.12 & 1 \\
\hline Module 2 & 521.75 & 261.22 & 1 \\
\hline Module 3 & 521.86 & 261.33 & 1 \\
\hline Module 4 & 522.62 & 262.10 & 1 \\
\hline Housing unity & 522.62 & $1,045.77$ & 4 \\
\hline
\end{tabular}


Table 6. State of the workstations for scenario 1.

\begin{tabular}{|c|c|c|c|c|}
\hline Workstations & Operation (\%) & Idle (\%) & Waiting (\%) & Blocked (\%) \\
\hline Alpha 1 & 26.29 & 73.71 & - & - \\
\hline Alpha 2 & 3.94 & 96.05 & - & - \\
\hline Alpha 3 & 20.87 & 79.11 & - & 0.01 \\
\hline Alpha 4 & 6.57 & 78.96 & 14.47 & - \\
\hline Alpha 5 & 5.63 & 81.33 & 13.04 & - \\
\hline Alpha 6 & 9.48 & 84.76 & 5.76 & - \\
\hline Alpha 7 & 16.31 & 83.69 & - & - \\
\hline Alpha 8 & 17.20 & 82.61 & - & 0.19 \\
\hline Alpha 9 & 24.43 & 72.27 & - & 3.29 \\
\hline Alpha 10 & 46.26 & 53.74 & - & - \\
\hline Alpha 11 & 31.78 & 68.22 & - & - \\
\hline Alpha 12 & 31.80 & 68.20 & - & - \\
\hline Alpha 13 & 26.50 & 73.50 & - & - \\
\hline Alpha 14 & 6.07 & 93.86 & - & 0.06 \\
\hline Alpha 15 & 28.63 & 71.34 & 0.03 & - \\
\hline Average & 20.12 & 77.42 & 4.76 & 0.71 \\
\hline Beta 1 & 10.94 & 89.06 & - & - \\
\hline Beta 2 & 25.81 & 74.19 & - & - \\
\hline Beta 3 & 25.71 & 39.60 & - & 34.69 \\
\hline Average & 20.82 & 67.62 & - & 34.69 \\
\hline Gamma 1 & 10.30 & 89.70 & - & - \\
\hline Gamma 2 & 22.34 & 77.66 & - & - \\
\hline Gamma 3 & 22.37 & 34.81 & - & 42.81 \\
\hline Average & 18.34 & 67.39 & 0.00 & 42.81 \\
\hline Delta 1 & 9.88 & 90.12 & - & - \\
\hline Delta 2 & 13.43 & 86.57 & - & - \\
\hline Delta 3 & 13.53 & 86.47 & - & - \\
\hline Delta 4 & 19.57 & 41.62 & & 38.81 \\
\hline Average & 14.10 & 76.20 & 0.00 & 38.81 \\
\hline System Average & 18.34 & 72.16 & 1.19 & 29.25 \\
\hline
\end{tabular}

In Table 6, one can see the waiting values at stations 4, 5 and 6, which, despite the high percentage of idleness and blockage, are not significant. This is because stations 4, 5 and 6 depend on the components of the feeding lines, which contributes to the increased idleness of the next workstations. This has been proven through the analysis of the dynamics simulation with ProModel ${ }^{\circledR}$ when it was possible to observe the modules on hold before and during processing in the stations that receive elements from the feeding lines. The analysis of Table 6 also shows that the system cycle time (housing unit) could be considerably lower once much time was spent in idleness and waiting.

Also according to the values on Table 6, it is noted the need for inclusion of a larger number of transporting resources (in this case, the platforms) so that the idle periods on the workstations are minimized. Waiting percentages are due to the production orders issued by the system (kanban). The system considers that the production of certain component was started, but, as there are not enough resources, the component 
is on standby in its respective station which, in this case, is always the first of the feeding lines. As by the results showed, it is possible to calculate the configuration efficiency for scenario 1. The efficiency of the system as a whole can be done using Equation 2, reproduced below:

$\mathrm{E}=\frac{\mathrm{WC}}{\mathrm{M} \times \mathrm{C}}$

The use of this equation depends, therefore, on the work content (WC), which is the sum of main line processing times, the number of the main line workstations $(M)$, and the cycle time (C). According to the sum of the values of the average processing time for the four modules, WC is identified by the value $1550.40 \mathrm{~min}$. The value of $\mathrm{M}$ is 15 workstations (considering that the feeders do not participate directly in the processing modules, being only components suppliers). The value of $C$ is $522.62 \mathrm{~min}$. in accordance with Table 5. Thus, the value of the line efficiency for scenario $1(E(1))$ is:

$\mathrm{E}(1)=\frac{1550.40}{15 \times 522.62}=0.1977=19.77 \%$

\subsection{Scenario 2 simulation}

For this scenario, the value of SI remains 67.42 , since there were no changes in the layout. As seen in scenario 1, the waste in the system (waiting and blockage), and in the value of the module cycle time and of the housing unit happen, mainly, because the model shows a scenario with a shortage of transport resources. So, the main line modules keep waiting for components, while the walls and slabs in the feeding lines are blocked. Thus, it is important to analyze the model behavior considering the variation in the number of platforms in the feeding line and in the main line, as well as the speed assigned to such resources.

This variation comprises the model optimization with a determined goal. In this case, the main objective is to reduce the system cycle time (house delivery) which, as demonstrated, implies the reduction of the production lead time and increased line efficiency (without changing the system layout). So, it is understood that, by reducing the flow of activities, the cycle time will also be reduced and the efficiency of the line is increased. Thus, the following optimization hypothesis was established: to reduce the delivery cycle time of the modules and minimize the waiting and idle times in the stations, it is necessary to increase the supply of assembly platforms on the main line and on the feeding lines, adjusting the transport velocity.

Thus, considering the optimization development as from the hypothesis, we used another ProModel $₫$ resource called SimRunner $\AA$ that provides the best configuration for the system according to the supplied input data (restrictions). SimRunner $®$ is used specifically for the models' optimization considering some objectives and constraints. The first step of optimization was the definition of objectives for the subsequent declaration of the variables involved. As stated, the optimization goal is the system's cycle time reduction, taking into account that, as seen in the results of scenario 1 , there is a high incidence of idleness on the workstations of all lines. Thus, for scenario 2 , the available objectives in SimRunner ${ }^{\circledR}$, and the ones chosen were: 1) to reduce the cycle time of the modules; 2 ) to minimize the idle time of all the feeding and main line stations. 
As stated, the SimRunner® offers an optimum situation for the model by varying the independent variables, developing experiments (simulations) that must converge to the best calculated objective function. Thus, the next optimization step was the definition of the variables involved. Table 7 shows the variables used in scenario 2 and the associated values limits. Altogether, SimRunner $®$ performed 165 experiments, which represented the interactions necessary for the convergence of variables as for the objectives already listed. With the results of the best experiment, it was possible to reconfigure the independent variables, whose optimal values are also in Table 7.

With the variables of the model properly reconfigured, the simulation started. The results of this second scenario are shown in Table 8 that lists the modules with their respective cycle times and overall production times.

Table 7. Independent variables involved in the optimization for scenario 2 and optimal values used.

\begin{tabular}{cccc}
\hline Variable & Lower limit & Upper limit & Optimal value \\
\hline Alpha line platforms & 1 unit & 52 units & 52 units \\
\hline Beta line platforms & 1 unit & 6 units & 6 units \\
\hline Gamma line platforms & 1 unit & 6 units & 6 units \\
\hline Delta line platforms & 1 unit & 8 units & 7 units \\
\hline Alpha line velocity & $0.83 \mathrm{~m} / \mathrm{s}$ & $2.78 \mathrm{~m} / \mathrm{s}$ & $1.81 \mathrm{~m} / \mathrm{s}$ \\
\hline Beta line velocity & $0.83 \mathrm{~m} / \mathrm{s}$ & $2.78 \mathrm{~m} / \mathrm{s}$ & $0.83 \mathrm{~m} / \mathrm{s}$ \\
\hline Gamma line velocity & $0.83 \mathrm{~m} / \mathrm{s}$ & $2.78 \mathrm{~m} / \mathrm{s}$ & $2.78 \mathrm{~m} / \mathrm{s}$ \\
\hline Delta line velocity & $0.83 \mathrm{~m} / \mathrm{s}$ & $2.78 \mathrm{~m} / \mathrm{s}$ & $2.78 \mathrm{~m} / \mathrm{s}$
\end{tabular}

Table 8. Cycle times of the modules and the housing unit for scenario 2.

\begin{tabular}{cccc}
\hline Product & $\begin{array}{c}\text { Average cycle time } \\
\text { (minutes) }\end{array}$ & $\begin{array}{c}\text { Average lead time } \\
\text { (minutes) }\end{array}$ & WIP max \\
\hline Module 1 & 242.27 & 121.59 & 7 \\
\hline Module 2 & 242.36 & 121.68 & 7 \\
\hline Module 3 & 242.46 & 121.79 & 7 \\
\hline Module 4 & 242.65 & 122.00 & 7 \\
\hline Housing unity & 242.65 & 487.06 & 28 \\
\hline
\end{tabular}

Comparing the results of Table 8 and Table 5 from the first scenario, it is noted that the cycle time of the housing unit has decreased $53.57 \%$ and the average lead time fell $53.42 \%$, which shows compliance with the first optimization goal. The WIP levels had an increase of 6 units for each module. To admit this increase in WIP, it is necessary to consider the increase in the distance between the workstations; in fact, this was considered in the computational model from its reprogramming regarding such distances, creating spaces for some modules inventory. The significant decrease of the cycle time and lead time occurred, mainly, on account of the increased supply of transport resources, coupled with the fact that the line velocities were adjusted to such an offer. On the other hand, the WIP levels for each module increased, which was expected, given the addition of the transport resources. Regarding the workstations, Table 9 shows the percentages concerning the behavior of the main line and feeding lines workstations. 
Table 9. State of the workstations for scenario 2.

\begin{tabular}{|c|c|c|c|c|}
\hline Workstations & Operation (\%) & Idle (\%) & Waiting (\%) & Blocked (\%) \\
\hline Alpha 1 & 56.57 & 2.07 & - & 41.36 \\
\hline Alpha 2 & 8.49 & 2.05 & - & 89.46 \\
\hline Alpha 3 & 45.02 & 1.28 & - & 53.69 \\
\hline Alpha 4 & 14.18 & 1.17 & 31.05 & 53.60 \\
\hline Alpha 5 & 12.15 & 1.18 & 28.08 & 58.60 \\
\hline Alpha 6 & 20.46 & 1.12 & 12.41 & 66.01 \\
\hline Alpha 7 & 35.09 & 0.92 & - & 64.00 \\
\hline Alpha 8 & 36.96 & 0.69 & - & 62.35 \\
\hline Alpha 9 & 52.71 & 0.54 & - & 46.74 \\
\hline Alpha 10 & 99.59 & 0.41 & - & - \\
\hline Alpha 11 & 68.53 & 31.47 & - & - \\
\hline Alpha 12 & 68.60 & 31.4 & - & - \\
\hline Alpha 13 & 56.87 & 43.13 & - & - \\
\hline Alpha 14 & 13.03 & 86.82 & - & 0.15 \\
\hline Alpha 15 & 61.74 & 38.19 & 0.07 & - \\
\hline Average & 43.33 & 16.16 & 7.96 & 53.60 \\
\hline Beta 1 & 23.56 & 8.19 & - & 68.24 \\
\hline Beta 2 & 55.60 & 5.63 & - & 38.77 \\
\hline Beta 3 & 55.34 & 6.66 & - & 38.00 \\
\hline Average & 44.83 & 6.83 & 0.00 & 48.34 \\
\hline Gamma 1 & 22.19 & 6.51 & - & 71.30 \\
\hline Gamma 2 & 48.02 & 5.82 & - & 46.16 \\
\hline Gamma 3 & 48.19 & 6.12 & - & 45.69 \\
\hline Average & 39.47 & 6.15 & 0.00 & 54.38 \\
\hline Delta 1 & 21.25 & 12.4 & - & 66.35 \\
\hline Delta 2 & 28.93 & 11.88 & - & 59.19 \\
\hline Delta 3 & 29.11 & 11.81 & - & 59.08 \\
\hline Delta 4 & 42.07 & 11.71 & - & 46.23 \\
\hline Average & 30.34 & 11.95 & 0.00 & 57.71 \\
\hline System Average & 39.49 & 10.27 & 1.99 & 53.51 \\
\hline
\end{tabular}

From Table 9, it is noted that the second optimization objective was also fulfilled. There is a considerable idle time reduction of the workstations in the feeding lines, with a decrease of $89.90 \%$ for the Beta line, $90.90 \%$ for the Gamma line and $84.32 \%$ for the Delta line. The reduction was also significant in the main line, with a decrease of $79.12 \%$. The blockage percentages of the stations suffered minor increases, which show the effectiveness of the model optimization. Taking the presented results into consideration, it is possible to calculate the efficiency of scenario 2 configurations, where the cycle time $(C)$ turns to $242.65 \mathrm{~min}$.

$\mathrm{E}(2)=\frac{1550.40}{15 \times 242.65}=0.4259=42.59 \%$ 
The results of this scenario show that the proposed objectives for the model optimization have been met and the hypothesis was confirmed. In fact, increasing the number of transport resources associated with an appropriate speed setting, led to an increase in the efficiency of the system as a whole, with a growth of $22.83 \%$ in the parameter. Additionally, waste, which in this case was identified by some flow activities, was also reduced.

\subsection{Scenarios 3 and 4 simulation}

Considering now the system layout, scenarios 3 and 4 suggest two changes in order to evaluate the production behavior. In these scenarios, transportation resource offerings remained the same as scenario 2 . In scenario 3 the following hypothesis was adopted: the elimination of the feeding lines to reduce the module cycle time and the waste percentages. Thus, in this scenario, the feeding lines were suppressed considering there was walls and roofs inventory for use in the main line. In scenario 4 , the following hypothesis was adopted: the elimination of workstations to reduce cycle time and increase system efficiency. Thus, stations 5 and 6 were suppressed and their tasks grouped in station 4 . In both scenarios, the variables settings from scenario 2 were maintained, subtracting those related to the feeding lines.

Considering scenario 3 , the value of SI remains 67.42 , since the substitution of feeder lines by element inventory did not change the processing times of the main line. The results showed that the cycle time of the housing unit, under the conditions of scenario 3, was 242.89 min, which can be equated with its pair in scenario 2 in terms of magnitude order, i.e., the variation was insignificant. The lead time assumed the value of 487.80 minutes ( 8.13 hours). The WIP values also remained the same as in scenario 2 . With regard to the workstations, the percentages related to operations, idleness waits, and blockages also remained very close to scenario 2 values, with minor differences. Concerning the efficiency of scenario 3 , it reached the value of $E(3)=42.55 \%$, which is almost the same as the previous scenario.

Pondering the configuration of scenario 3 with the results of its simulation, it can be stated that the adoption of the feeding lines in a flow shop system is essential when the reduction of cycle times is desired. Indeed, if the stations of these lines were in the main line, the delivery cycle of the units would be higher. This was confirmed by the results of scenario 3 , wherein the system cycle time remained very close to scenario 2 . Thus, the hypothesis of scenario 3 was rejected.

In scenario 4, stations 5 and 6 were deleted and their activities were grouped in station 4 , whose cycle time increased (31.5 minutes), since it is necessary to obey the sequence of walls and roofs assembly. In addition, with this layout modification, the SI value became 44.65 . This new SI value shows a $33.77 \%$ improvement over the layout of scenario 1 , indicating a better distribution of tasks. Although the station processing time has increased, the housing unit cycle time was 242.81 minutes and the lead time was 487.20 minutes ( 8.12 hours), values also very close to scenario 2 . Also for scenario 4 , WIP values remained identical to scenario 2. As regards the workstations, the percentages related to operations, idleness, waits and blockages also remained very close to the values of scenario 2 , with minor differences. Concerning the efficiency of scenario 4 settings, it reached the value of $E(4)=49.12 \%$, representing an increase of $15.5 \%$ compared to scenario 2 , because the $\mathrm{WC}$ is the same and $\mathrm{M}$ is smaller (13 stations). Thus, scenario 4 hypothesis was partially confirmed, once the cycle time is not significantly modified, but the system efficiency has actually increased. 
In this sense, we note that changes in the distribution of tasks in the main line become insignificant in the proposed system when the goal is to reduce the cycle times. Obviously, the reduction of workstations results in other direct benefits such as reduced operational costs, space saving and, as seen, system efficiency.

\section{Discussion of simulation results}

Regarding the simulations, and considering the use of feeding lines in order to avoid inventory elements, it was found that the best configuration is that defined by scenario 2. Its definitions compared to other scenarios show that it is possible to assemble a house, similar to that presented in this article, in about $487 \mathrm{~min}$. (8.12 hours), with delivery cycles of $242.65 \mathrm{~min}$., resulting in a theoretical efficiency of $42.59 \%$. The other scenarios, except the first, showed very similar results to scenario 2. Scenarios 3 and 4 combined changes related to the layout of the proposed system. However, it was seen that the withdrawal of feeding lines (scenario 3 ) and the reduction of workstations (scenario 4) did not cause significant impacts on the housing unit cycle time, being thus possible to conclude that the main line was satisfactorily structured and at its maximum capacity, in view of the settings of its stations.

It should be noted that scenario 4 showed a significantly better theoretical efficiency, represented by the value of $49.12 \%$, although its settings resulted in a unit cycle time almost similar to scenario 2 . This was due to the reduction from 15 to 13 workstations, ensuring better performance in terms of efficiency, also considering that the feeding lines were deleted. Thus, it can be said that, given the elimination of inventory elements (walls and roofs) with the use of the feeding lines, scenario 2 presents the best configuration. Considering the storage of these elements, and eliminating the feeding lines, scenario 4 has the best configuration.

Concerning the waste, these indexes remained nearly unchanged in scenarios 2,3 and 4 , in view of the optimization results in scenario 2 . With the optimization, there was a decrease of idleness on the workstations in all the lines. The levels of WIP, despite having increased in relation to scenario 1 , also kept stable thanks to the adoption of JIT as a concept for the coordination system of production orders. The graph in Figure 3 summarizes the results for the parameters measured in the housing unit simulations.

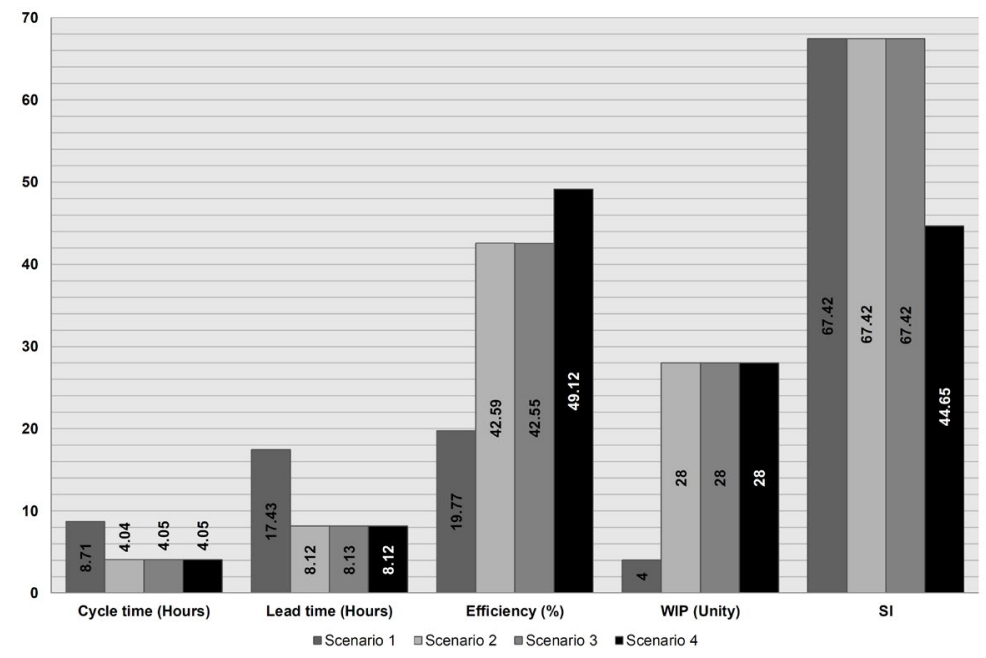

Figure 3. Variables measured in different scenarios. 
Although production orders obey the JIT concept, the high percentages of blocking and waits in some scenarios can be explained by the fact that there are considerable differences between the processing times of the workstations $(\mathrm{SI}=67.42$ for scenarios 1,2 and 3 , and $\mathrm{SI}=44.65$ for scenario 4 ). Thus, although the system sends production orders only when the products leave the system, these orders are directed to the modules, so that immediately after the production order for module 1, the order for module 2 is sent and so on. Due to the disparities between the processing times in the line, the waiting and blocking times begin to accumulate, generating higher levels of WIP as the orders are released. The best way to solve this problem is to promote assembly line balancing, in order that the SI value is equal to or near zero, but this solution involves issues related to the Assembly Line Balancing Problem whose methodologies are beyond the scope of this article, which can lead to significant changes in layout.

\section{Conclusions}

With the results of the article, it can be said that the research questions previously identified were answered. The first question was related to the identification of the layout of the production system for housing units in LGSF. This was solved with the proposal of the production system, which was validated in terms of technological constraints of the building system and in terms of operation through computer simulation. The second question suggested an investigation of the cause and effect relationships in the system as a whole, so this was also analyzed in the article through the behavior of the different simulation scenarios. The third question was related to which configuration allowed a better utilization between the variables and characteristics of the system, which was also answered in function of the analysis of the efficiency of each scenario. Once these questions were answered, the main objectives of the article were also achieved, that is, the production system was developed, validated and optimized.

Thus the contribution of this article's results, both in academic and practical levels can be identified in three main points. The first is the definition of a specific production layout for LGSF housing units, a fact little explored in the literature with unimpressive results from the point of view of the assembly lines concept. The second point refers to the results of the computer simulations, which allowed the study of the stochastic behavior in each scenario and, thus, understand the cause and effect relation between the variables of the models, ensuring harmony among the elements of the system. The third point relates to the indication of the best configuration of the production system, which is the ideal performance situation facing issues such as lower delivery cycle times of the units and waste reduction, represented by flow activities.

In addition, as mentioned in the topics related to Introduction and Research Gap, it was noted the lack of publications that addressed the use of LGSF as a technology for the production of dwellings in assembly lines and the presentation of new production systems dedicated exclusively to this objective. Thus, it is understood that the present article fulfilled the research gaps indicated by the fact that it presented, validated and analyzed a production system based on assembly lines, sized and adapted to enable the execution of assembly techniques inherent to the LGSF in workstations and production cells, contributing positively to both academia and the market, providing parameters, at least initials, for new researches and investors in the real estate market. 
The layout development and the results presented by the simulations show that it is perfectly possible to implement more effective means of production that are not part of the construction routine in most countries. Associated to this, the LGSF building system supports the increase of the quality of the buildings, in view of the industrialization characteristics of its components. Additionally, an important point to be noted concerns the flexibility of the proposed production system. Although the simulations were performed for the assembly of modules that form a housing unit, the production system could also be used only for walls assembly, for example, resulting in lower cycle times. Also regarding the system flexibility, in principle, any single house model can be delivered by the production system, provided that the issues relating to modularization and building system requirements are met. Therefore, it is possible to deliver a wide range of models that can supply different types of market.

The time assigned to the workstations can be effectively reduced, even without automation, as the learning factor and the experience of the teams directly influence the behavior of the workstations. In addition, interventions that were not included in the models such as increased number of workers, simplification of the activities, mechanization, among others, may also imply a reduction in lead time and increased system efficiency.

Finally, in order to promote research and advances on what has been presented in this article, the following topics are recommended for future researches: mechanization and robotization of the activities; study of the impact of the supply chain and storage of parts and elements in the proposed system; impact of the variation of the transportation velocities on the system performance; layout optimization for waste reduction; change of building system, such as Wood Frame, for comparison; study of the costs of the housing unit associated with the characteristics of the system; technologies for automating assembly activities of the LGSF.

\section{References}

Aized, T. (2010) Material handling in flexible manufacturing system. In: T. Aized (Ed.), Future manufacturing systems (pp. 121-137). London: Intech.

Arturo Garza-Reyes, J., Oraifige, I., Soriano-Meier, H., Forrester, P. L., \& Harmanto, D. (2012). The development of a lean park homes production process using process flow and simulation methods. Journal of Manufacturing Technology Management, 23(2), 178-197. http://dx.doi.org/10.1108/17410381211202188.

Banerjee, D., Syal, M., \& Hastak, M. (2006). Material flow-based facility layout analysis of a manufactured housing production plant. Journal of Architectural Engineering, 12(4), 196206. http://dx.doi.org/10.1061/(ASCE)1076-0431(2006)12:4(196).

Banks, J. (1999). Introduction to simulation. In Proceedings of the 1999 Winter Simulation Conference (Vol. 1, p. 7-13). New York: Association for Computing Machinery. http://dx.doi.org/10.1145/324138.324142.

Bautista, J., \& Pereira, J. (2007). Ant algorithms for a time and space constrained assembly line balancing problem. European Journal of Operational Research, 177(3), 2016-2032. http://dx.doi.org/10.1016/j.ejor.2005.12.017.

Bertelsen, S., Henrich, G., Koskela, L., \& Rooke, J. (2008). Construction physics. In Proceedings of the 15th Annual Conference of the International Group for Lean Construction. UK: University of Huddersfield. Retrieved in 2018, October 22, from http://eprints.hud.ac.uk/id/eprint/25958/1/BertelsenHenrichKoskelaRooke2007_Constructio n_Physics 
Creswell, J. W. (2010). Mapping the developing landscape of mixed methods research. In: A. Tashakkori \& C. Teddlie (Eds.), Sage handbook of mixed methods in social \& behavioral research (Vol. 2, pp. 45-68). Thousand Oaks: Sage. http://dx.doi.org/10.4135/9781506335193.n2.

Dooley, K. (2002). Simulation research methods. In J. Baum (Ed.), Companion to organizations (pp. 829-848). London: Blackwell.

Hammad, A. A. (2001). Simulation modeling for manufactured housing processes (Master's Thesis). University of Cincinnati, Cincinnati.

Hammad, A. A., Hastak, M., \& Syal, M. (2004). Comparative study os manufactured housing production system. Journal of Architectural Engineering, 10(4), 136-142. http://dx.doi.org/10.1061/(ASCE)1076-0431(2004)10:4(136).

Hammad, A., Salem, O., Hastak, M., \& Syal, M. (2008). Decision support system for manufactured housing facility layout. Journal of Architectural Engineering, 14(2), 36-46. http://dx.doi.org/10.1061/(ASCE)1076-0431(2008)14:2(36).

Hopp, W. J., \& Spearman, M. L. (2008). Factory physics (3rd ed.). USA: McGraw-Hill/Irwin

Jeong, J. G., Hastak, M., Syal, M., \& Hong, T. (2011). Internal relationship modeling and production planning optimization for the manufactured housing. Automation in Construction, 20(7), 864-873. http://dx.doi.org/10.1016/j.autcon.2011.03.003.

Koskela, L. (2000). An exploration towards a production theory and its application to construction. Finland: VTT Technical Research Centre of Finland.

Koskela, L. (2011). Lean construction as a movement towards theory-based construction management. UK: SDPublishing.

Koskela, L., \& Vrijhoef, R. (2001). Is the current theory of construction a hindrance to innovation? Building Research and Information, 29(3), 197-207. http://dx.doi.org/10.1080/09613210110039266.

Lane, G. (2007). Made-to-order lean: excelling in a high-mix, low-volume environment. UK: Productivity Press.

Law, A. M., \& Kelton, W. D. (2000). Simulation modeling and analysis. Boston: McGraw Hill.

Long, Q., \& Zhang, W. (2014). An integrated framework for agent based inventory-productiontransportation modeling and distributed simulation of supply chains. Information Sciences, 277, 567-581. http://dx.doi.org/10.1016/j.ins.2014.02.147.

Mehrotra, N., Syal, M., \& Hastak, M. (2003). Manufactured housing production process and layout design. Bridges, 10(40671), 1-8. http://dx.doi.org/10.1061/40671(2003)43.

Mehrotra, N., Syal, M., \& Hastak, M. (2005). Manufactured housing production layout design. Journal of Architectural Engineering, 11(1), 25-34. http://dx.doi.org/10.1061/(ASCE)10760431(2005)11:1(25).

Miltenburg, J. (2001a). U-shaped production lines: a review of theory and practice. International Journal of Production Economics, 70(3), 201-214. http://dx.doi.org/10.1016/S09255273(00)00064-5.

Miltenburg, J. (2001b). One-piece flow manufacturing on U-shaped production lines: a tutorial. IIE Transactions, 33(4), 303-321. http://dx.doi.org/10.1080/07408170108936831.

Müller, B. C., Menn, J. P., \& Seliger, G. (2017). Procedure for experiential learning to conduct material flow simulation projects, enabled by learning factories. Procedia Manufacturing, 9 , 283-290. http://dx.doi.org/10.1016/j.promfg.2017.04.047.

Rekiek, B., \& Delchambre, A. (2006). Assembly line design: the balancing of mixed-model hybrid assembly lines with genetic algorithms (Springer Series in Advanced Manufacturing). UK: Springer-Verlag. 
Schmitz, J. P. M., Van Beek, D. A., \& Rooda, J. E. (2002). Chaos in discrete production systems? Journal of Manufacturing Systems, 21(3), 236-246. http://dx.doi.org/10.1016/S0278-6125(02)80164-9.

Scholl, A. (1999). Balancing and sequencing of assembly lines. Physica-Verlag Heidelberg. http://dx.doi.org/10.1007/978-3-662-11223-6.

Senghore, O., Hastak, M., Abdelhamid, T. S., Abuhammad, A., \& Syal, M. (2004). Production process for manufactured housing. Journal of Construction Engineering and Management, 130(5), 708-718. http://dx.doi.org/10.1061/(ASCE)0733-9364(2004)130:5(708).

Tompkins, J. A., \& White, J. A. (1984). Facilities planning. New York: John Wiley.

Veljkovic, M., \& Johansson, B. (2006). Light Steel Frame for residential buildings. Thin-walled Structures, 44(12), 1272-1279. http://dx.doi.org/10.1016/j.tws.2007.01.006.

White, K. P., Jr., \& Ingalls, R. G. (2009). Introduction to simulation. In Proceedings of the 2009 Winter Simulation Conference. New York: Association for Computing Machinery. http://dx.doi.org/10.1109/WSC.2009.5429315. 